\title{
Does participation in adult education increase volunteering? An analysis of British longitudinal data
}

\author{
Ina Rüber and Jan Germen Janmaat
}

\begin{abstract}
High-quality longitudinal data from the UK Household Longitudinal Study (UKHLS) gives us the opportunity to investigate whether participation in adult education (AE) fosters volunteering, and whether this depends on the volume of $\mathrm{AE}$, its content, or on the qualification obtained with it. From a public enlightenment perspective, we would only expect to find an effect if the content of $\mathrm{AE}$ relates to social issues and domains relevant for volunteering. Yet, theories emphasizing $\mathrm{AE}$ as a place of encounter and an activity that strengthens self-confidence would expect a positive effect regardless of the content but depending on the volume and the obtained qualification. Our results from a person fixed-effects model reveal a significant and positive effect of participation in adult education on volunteering in general, while volume, content and obtained qualifications appear to make no difference. These findings provisionally suggest that social interactions and self-perceptions explain civic returns to adult education.
\end{abstract}

Keywords: adult education, non-monetary returns, Understanding Society, training, volunteering 
Does participation in adult education increase volunteering?

Research on adults' engagement in educational activities beyond initial full-time education repeatedly reports a positive association between participation in adult education (AE) and civic engagement, like active involvement in the community through club memberships or through political activities (Dolan, Fujiwara, \& Metcalfe, 2012; Panitsidou, 2012; Schuller, Preston, Hammond, Brassett-Grundy, \& Bynner, 2004; Thomas, 2017; Vera-Toscano, Rodrigues, \& Costa, 2017). Whether the association is causal and why AE would exert this effect on civic participation, however, remain only partially resolved questions. A causal effect is to be expected in view of the historical roots of AE. They go back to social movements successfully using education to enhance adults' engagement with political and social affairs (AUTHOR 2 \& ANOTHER, 2013; Olbrich, 2001). However, as employability has increasingly come to replace civic maturity as the main objective of AE (Bynner, 2017), a causal interpretation of the association seems less reasonable. The majority of AE activities are purely job-related or take place at the workplace itself (Bilger, Behringer, Kuper, Schrader, 2017; Boeren, 2017; Dieckhoff, Jungblut, \& O’Connell, 2007).

Earlier research arguing for a causal effect, employed either qualitative methods (e.g. Tønseth, 2015), which do not allow for generalizable results, or they relied on cross-sectional or two-wave panel data (e.g. Feinstein, Hammond, Woods, Preston, \& Bynner, 2003; Paterson, 2009), which have their clear limitations in identifying causality and controlling for unobserved heterogeneity. A recent article by Ruhose and colleagues (2019) significantly advanced the research field, presenting findings from an in-depth longitudinal analysis using German panel data. Even with very restrictive models, the authors identified a positive effect of participation in job-related training on civic/political participation and cultural participation. They further 
Does participation in adult education increase volunteering?

provide indicative evidence for potential mechanisms explaining the effect. Training participation may foster the structural dimension of social capital, the development of new social ties, which in turn increases possibilities for civic participation.

The current study builds on these recent findings. It provides quantitative evidence for an effect of AE on volunteering using multiple-wave panel data from the Understanding Society the UK Household Longitudinal Study (UKHLS). Moreover, it aims to further the discussion on mechanisms that could explain this effect by distinguishing different types of $\mathrm{AE}$ based on content, volume and accreditation. Following AUTHOR 1 and OTHERS (2018), the type of AE is indicative of the mechanisms explaining the link between $\mathrm{AE}$ and volunteering.

Contrary to earlier research (e.g. Ruhose, Thomsen, \& Weilage, 2019; Schuller et al., 2004), we chose to focus on one single outcome, namely volunteering. Volunteering is a wellapproved measure of civic participation (Son \& Lin, 2008). It is the voluntary and unpaid work for associations, parties, or clubs and it is considered essential for a functioning democracy (Putnam, 2000; Priemer, Krimmer, \& Labigne, 2017). It relates to individuals' economic success (Qvist \& Munk, 2018), a sense of belonging and psychological well-being (Dolan, Peasgood, \& White, 2008). Besides extensive research on the determinants of volunteering (Bekkers, 2005; Einolf \& Chambré, 2011; Hustinx, Cnaan, \& Handy, 2010; Wilson, 2012) changes in volunteering during adulthood have not yet been fully accounted for (Lancee \& Radl, 2014; Oesterle, Johnson, \& Mortimer, 2004; Rotolo, 2000; Wiertz, 2016).

Our major contribution is to show that participation in adult education in general is positively associated with individual change in volunteering, and that the content, qualification or volume of AE hardly matter. As outlined in the course of this paper, our findings provisionally 
Does participation in adult education increase volunteering?

support the idea that $\mathrm{AE}$ mainly fosters volunteering by allowing participants to enlarge their social circle (as also suggested by Ruhose et al., 2019) and to enhance their self-efficacy.

\section{Determinants of change in Volunteering}

Explanations for changes in volunteering behaviour during adulthood often connect to social network theories and social role theories. Social networks influence the decision to start volunteering in two ways. First, the composition of social networks matter, because volunteering becomes less likely, the greater the social distance to the beneficiaries of the act of volunteering is (Bekker, 2010). If potential beneficiaries of volunteering somehow connect to one's social network, volunteering becomes more likely. Second, the larger a social network is, the greater are the chances to be recruited as a volunteer. Whether or not someone is asked to volunteer depends not only on personal characteristics but also on the frequency of interactions and the types of discussions held with others (Beyerlein \& Bergstrand, 2016). Individuals with small social networks may also be motivated to start volunteering to get to know more people. However, recruitment has been shown to be the stronger determinant of starting volunteering (Wilson, 2012).

From the perspective of social role theory, volunteering may be regarded as a social role itself, which satisfies social and emotional needs. But it also requires time and therefore stands in conflict with activities connected to other social roles (Hank \& Stuck, 2008). Which social role an individual takes up connects to the preferences but also to life-course transitions, such as becoming employed, parenthood or having to care for a relative. Life-course transitions connected to the family domain have been found to matter the most to explain changes in volunteering behaviour (Knoke \& Thomson, 1977; Lancee \& Radl, 2014; Rotolo, 2000). Especially women's volunteering drops from the age of 20 until the age of 30, where the 
Does participation in adult education increase volunteering?

attention may lie on family creation, child-rearing or financial provision. Throughout the life course, though, those who started volunteering early in life also tend to have higher chances for volunteering later in life (Greenfield \& Moorman, 2018; Kim \& Morgül, 2017).

Social networks and social roles also connect to Wiertz' (2016) volunteering and membership market model. This model posits that volunteering is a function of individuals' resources and preferences and the opportunities that voluntary organisations provide. The condition on the supply side restricts the potential of adult learning to increase volunteering. Even if AE changed individuals' resources or preferences, it may not exert an effect on actual volunteering if there are no possibilities for volunteering. This is not to be expected in the British context. In comparison to other European countries, the UK has an exceptionally advanced voluntary sector that is associated with a longstanding volunteering tradition (Mathou, 2010). Within a period of 12 months, 38\% of its adult population take part in volunteering (McGarvey et al., 2019). Therewith it is among the group of countries where levels of volunteering are highest (the other countries being Austria, The Netherlands and Sweden) (Mathou, 2010). Among those who volunteer in the UK, popular activities are raising and/or handling money (65\%), organising or helping to run an event (50\%), offering other practical help (35\%) and taking part in a committee or board (28\%) (Low et al., 2007). Only a negligible share of UK citizens report to have difficulties in finding volunteer opportunities (Hornung, 2018).

\section{How adult education affects determinants of change in Volunteering}

In a theoretical framework relating to the civic returns on adult learning, AUTHOR 1 and OTHERS (2018) connect explanations for change in volunteering with the known outcomes of participation in AE. The framework suggests four mechanism clusters through which AE may influence civic participation: (1) AE may shape the learners' competences for volunteering and 
Does participation in adult education increase volunteering?

the perceived benefits to the act of volunteering; (2) it may change the learners' self-perceptions that are relevant for the uptake of new activities, such as self-efficacy or self-esteem; (3) it may affect the learners' attitudes and values related to the society; (4) it takes place in social contexts and thereby provides the opportunity to expand the learners' social networks and communities. Whether or not a mechanism sets in and to what extent it is prevalent, is conditional on the characteristics of the AE activity (AUTHOR 1 \& OTHERS, 2018).

Inherent to participation in $\mathrm{AE}$ of all types are opportunities to expand social networks, since AE takes place within a social context. Earlier research showed that AE participants take advantage of these opportunities and establish new contacts among the other participants (Balatti \& Falk, 2002; Fujiwara, 2012; Manninen, Fleige, Thöne-Geyer, \& Kil, 2014; Power, Neville, \& O'Dwyer, 2011). This increases the chance for volunteering as outlined before. Participation in AE of all types may also enhance one's self-efficacy via increased confidence in one's achievement (Hammond \& Feinstein, 2005; Tett \& Maclachlan, 2007). In turn, self-efficacy is conducive to taking up volunteering, not only because it represents the belief that one can complete the volunteering tasks successfully but also because it strengthens the motivation to volunteer, such as the desire to improve things and to help others (Hornung, 2018). Hence, AE of all types increases the propensity for individuals to take up volunteering (Hypothesis 1).

Following earlier research (Feinstein et al., 2004; AUTHOR 1 \& OTHERS, 2018), we postulate that the effect depends on three further dimensions of AE: qualification, volume, and content. The first two dimensions relate to resources. AE leading to a new qualification can yield enhanced monetary returns and thereby change individual's resources for volunteering (Hanushek, Schwerdt, Woesmann, \& Zhang, 2017). From an economic point of view, a sufficiently high income is a precondition to volunteering. Volunteering is unpaid work, which 
Does participation in adult education increase volunteering?

people are only likely to take on if their paid work equips them with both sufficient time and money to engage in these activities. We also propose that courses culminating in a qualification are particularly apt at increasing self-efficacy. Therefore, we expect courses leading up to a new qualification to have a stronger impact on volunteering than courses not leading up to a qualification (Hypothesis 2). Regarding the volume of AE experienced, the greater the degree of exposure to $\mathrm{AE}$, the greater will be the opportunities to build up new contacts and selfconfidence (Feinstein et al., 2003; Ruhose et al., 2019). We presume, therefore, that the more time spent on a course, the greater the impact on volunteering should be (Hypothesis 3).

Regarding content, existing research suggests that $\mathrm{AE}$ representing distinct pedagogies and promoting public enlightenment can be effective in changing people's values, attitudes and dispositions and hence their preferences (De Greef, Verté, \& Segers, 2015; Desjardins, 2017; Paterson, 2009; Vera-Toscano et al., 2017). Analysing British longitudinal data, Paterson (2009), for instance, found a positive effect of $\mathrm{AE}$ courses in the social sciences and humanities on socially liberal values and civic participation. We postulate that content that relates to societal matters and that aims at enhancing public engagement is especially effective in triggering an attitudinal change culminating in a disposition to volunteer. This is because such content is likely to enhance an awareness of pressing social problems and an understanding of actions needed to address such problems, which in turn fuel the motivation to become engaged (Niemi \& Junn, 1998; Lauglo \& Oia, 2006; Paterson, 2009). We conjecture that such topics are more likely to be addressed in non-job than in job-related AE. By implication, the effect of job-related AE on starting to volunteer should be smaller as compared to non-job-related AE (Hypothesis 4). 
Does participation in adult education increase volunteering?

Hence, our main research questions, which we will address empirically in the following analysis, are whether participation in $\mathrm{AE}$ increases the chance to start volunteering and if so, whether this effect is mediated by the content, volume and achieved qualification of AE.

\section{Data and Methods}

To test the effect of $\mathrm{AE}$ and its different dimensions on volunteering, we use unique contemporary panel data from the UKHLS (University of Essex, Institute of Social and Economic Research, NatCen Social Research and Katar Public, 2017). The UKHLS started its annual 24 months period data collection in 2009/10 in succession of the last wave of the British Household Panel Survey (BHPS). With computer aided personal interviews, the UKHLS collects high-quality data from a UK representative sample consisting of members (in the age of 10 and above) from approximately 40,000 households (General Population Sample (GPS). The UKHLS also follows up former BHPS sample members (up from Wave 2) and includes a general population comparison sample (GPCS) that effectively is a random sample of the GPS. Further, it provides immigrant and ethnic minority boost samples (EMBS \& IEMBS (wave 6)). We restrict our analytical sample to the GPS sample for the main analysis of this paper, since we aim to identify the general effect of adult education on volunteering rather than subgroup-effects.

The UKHLS adult survey questionnaires (completed by respondents in the age of 16 and above) address a rich set of subject areas, ranging from health to education, work, income, family and social life. Information on adults' participation in education is part of the annually posted main questionnaire up from the second wave. Information on adults' volunteering is part of a bi-annually posted questionnaire. We use three waves that include information on volunteering: 2010/11;2012/13;2014/15 (waves 2, 4 and 6). We restrict our sample to adults above the age of 25 to ensure comparability to other studies, which often use the same age range. 
Does participation in adult education increase volunteering?

We further avoid problems of heterogeneous samples by age groups, since we also exclude fulltime students from the analysis. We only include respondents that took part in at least two consecutive waves in our sample to track individual change in participation in $\mathrm{AE}$ and volunteering. After the deletion of all missing values, we are left with 62,569 observations, which are drawn from 23,202 respondents. The supplementary material provides detailed information on the derivation of the analytic sample. $57 \%$ of the sample are female. $15 \%$ hold no educational qualification, $30 \%$ reach level 1 or 2 and $25 \%$ reach level 6 and above, classified according to the UK qualification levels ${ }^{1}$ (see further below for a more extensive description of the sample).

Lynn and Borkowska (2018) provide a detailed analysis on panel attrition in the UKHLS GPS sample as compared to the BHPS. They show that after six years only $52 \%$ of the initial sample take part in the survey. However, the initial sample reached higher representativeness than the BHPS sample did. The attrition patterns are the same and result in underrepresentation of the youngest age groups, men, black people, people with lower incomes, and people living in London. Our hypotheses in this study do not involve any assumptions about differences between these groups. Nevertheless, we acknowledge that our results may not be fully generalizable to the UK population.

\section{Variables}

To measure volunteering, we relied on the question asking respondents whether they have given any unpaid help or worked as a volunteer for any type of local, national or international organisation or charity in the last year [yes; no]. Accordingly, we tapped our outcome of interest with a dummy variable. 
Does participation in adult education increase volunteering?

We measure participation in $\mathrm{AE}$ and its three dimensions, volume, qualification, and content distinctively. Participation in AE is tapped with a dummy variable asking whether the respondent took part in any training program or course since the last interview $(1=$ yes; $0=$ no $)$. The period between the current and the last interview is approximately equivalent to a 12 months period, since participation in $\mathrm{AE}$ is part of the annually posed questionnaire. The interviewer provides a few examples for $\mathrm{AE}$ activities: part-time evening courses, employer provided training, day release schemes, and government training schemes.

The survey asks respondents to indicate how many distinct courses they took part in and to state their attendance for up to three of the mentioned courses (in the number of days and the number of hours per day). In case the respondent participated in more than three courses, (s)he is requested to give information on his/her attendance for the three most time-intensive courses. We constructed the volume of $\mathrm{AE}$ variable by first multiplying (for each course) the number of attendance days with the average hours per attendance day and then by adding up these multiplications for the three courses.

For each of the three courses, the respondents indicate whether the course culminated in a qualification or not. To measure the qualification dimension of $\mathrm{AE}$ we construct a dummy variable, where 1 indicates that at least one AE activity culminated in a qualification and 0 means that the respondent did not take part in $\mathrm{AE}$ or that no course led to a qualification.

For each of up to three courses the respondents indicate their purposes for participation. They are able to choose as many purposes as they believe to be appropriate out of a list containing seven options ${ }^{2}$. The first five are clearly job-related, while the remaining two are predominantly non-job-related. Using this information, we construct three dummy variables approximating the course content: doing $\mathrm{AE}$ (1) for job-related purposes [1=yes; $0=$ no], (2) for 
Does participation in adult education increase volunteering?

non-job-related purposes [1=yes; $0=$ no], and (3) for both job and non-job related purposes $[1=$ yes; $0=$ no]. The value 0 of each of these variables denotes either respondents who do not participate in $\mathrm{AE}$ or who belong to one of the other categories (e.g. the value 0 for the dummy on job-related purposes denotes non-participants or participants doing AE for non-job related purposes or participants doing AE for both purposes).

Earlier research showed that there are several common determinants of volunteering and participation in adult education, such as an individual's educational level (Desjardins et al., 2006; Niebuur et al., 2018). The identification of an effect of adult education on volunteering calls for controlling for these common determinants. The models that we apply on the data automatically control for the time-invariant factors (such as initial education). Hence, we only construct control variables for the time-varying common determinants, which we will subsequently include in the models. The control variables we chose on the basis of relevant review studies and reports (e.g. Bilger et al., 2017; Bekkers, 2005; Wilson 2012) can be broadly summarized as proxies for general interest in politics, living and health conditions, employment situation and potential year specific current affairs.

Table 1 provides an overview of all variables and their main summary statistics that we calculate using the total analytical sample of all variables. The within-standard deviations show that the values of each variable change within individuals over time. Across the three waves $21 \%$ of the respondents indicated having volunteered in the last year. This percentage is much lower as compared to the earlier mentioned $38 \%$. We assume this to be the case, because the UKHLS has a large questionnaire in which volunteering gets very little notice. Respondents might not remember all their activities if they do not have a large meaning in their lives. The vast majority 
Does participation in adult education increase volunteering?

of the sample are in work (56\%) or retired (31\%). These relatively high percentages make sense if we consider the average age of the sample, which is almost 54.

Table 1. Descriptive statistics of dependent, independent and control variables for the pooled longitudinal sample.

\begin{tabular}{|c|c|c|c|c|c|}
\hline & $\%$ & Mean & Std. Dev. & Within-person-Std. Dev. & Range \\
\hline \multicolumn{6}{|l|}{ Outcome } \\
\hline Volunteering & 21 & & .41 & .23 & $0 / 1$ \\
\hline \multicolumn{6}{|l|}{ Adult Education } \\
\hline Participation & 22 & & .42 & .27 & $0 / 1$ \\
\hline Job-related & 14 & & .35 & .24 & $0 / 1$ \\
\hline Mixed (ref cat) & 5 & & .22 & .16 & $0 / 1$ \\
\hline Non-job-related & 3 & & .17 & .12 & $0 / 1$ \\
\hline Qualification & 8 & & .27 & .20 & $0 / 1$ \\
\hline Volume & & 11.29 & 46.54 & 34.07 & $0-2080$ \\
\hline \multicolumn{6}{|l|}{ Controls } \\
\hline Other volunteer in hh & 16 & & .37 & .22 & $0 / 1$ \\
\hline Interest in politics & 48 & & .50 & .25 & $0 / 1$ \\
\hline Good health & 78 & & .42 & .22 & $0 / 1$ \\
\hline Child in hh & 18 & & .38 & .11 & $0 / 1$ \\
\hline Moved houses & 5 & & .22 & .17 & $0 / 1$ \\
\hline Change in employment & 4 & & .20 & .15 & $0 / 1$ \\
\hline Caring for someone & 21 & & .41 & .24 & $0 / 1$ \\
\hline Age & & 53.90 & 15.33 & 1.54 & $26-104$ \\
\hline Net income & & 1572.81 & 1405.70 & 759.86 & $-8851.81-15000$ \\
\hline \multicolumn{6}{|l|}{ Marital Status } \\
\hline Single & 17 & & .38 & .10 & $0 / 1$ \\
\hline Married & 61 & & .49 & .13 & $0 / 1$ \\
\hline Separated/widowed & 22 & & .41 & .12 & $0 / 1$ \\
\hline \multicolumn{6}{|l|}{ Living } \\
\hline Alone & 22 & & .42 & .14 & $0 / 1$ \\
\hline With partner & 71 & & .45 & .14 & $0 / 1$ \\
\hline With other adult & 6 & & .24 & .11 & $0 / 1$ \\
\hline \multicolumn{6}{|l|}{ Employment status } \\
\hline Self-/employed & 56 & & .50 & .18 & $0 / 1$ \\
\hline Unemployed/disabled & 7 & & .26 & .13 & $0 / 1$ \\
\hline Pensioner & 31 & & .46 & .14 & $0 / 1$ \\
\hline Homemaker/else & 6 & & .24 & .13 & $0 / 1$ \\
\hline \multicolumn{6}{|c|}{ Subjective financial difficulties } \\
\hline No & 67 & & .47 & .26 & $0 / 1$ \\
\hline Some & 24 & & .43 & .28 & $0 / 1$ \\
\hline Yes & 9 & & .29 & .18 & $0 / 1$ \\
\hline \multicolumn{6}{|l|}{ Year } \\
\hline $2010 / 2011$ & 34 & & .47 & .46 & $0 / 1$ \\
\hline $2012 / 2013$ & 37 & & .48 & .48 & $0 / 1$ \\
\hline $2014 / 2015$ & 29 & & .46 & .44 & $0 / 1$ \\
\hline
\end{tabular}

Source: Own calculations using UKHLS waves 2, 4 and 6.

Note: Total analytical sample pooled over three waves, $\mathrm{N}=62,569$ 
Does participation in adult education increase volunteering?

\section{Analytical strategy}

We model the effect of adult education on volunteering using linear person-fixed effects regressions. The advantage of such regressions is that they automatically control for all timeinvariant influences on the outcome of interest (Halady 2004). They are thus more robust in relation to problems of unobserved heterogeneity than cross-sectional analyses. The fixed effect estimation generally resembles a linear regression model, but instead of using the actual values of the variables, the values are subtracted from the individual grand mean, which is calculated using the observations from the same individual at the different time points. Consequently, all time-invariant variables get the value 0 and drop out of the model. Applying these models, we hence model the associations of within person changes in the AE factors on within person changes in volunteering.

For the presentation of the results in this article, we choose linear regressions over other estimation techniques for binary outcomes as this enables us to directly interpret the coefficients and compare them between different models, which is not possible in logistic regressions (Mood 2010). While this strategy finds support in the work of some scholars (Gomila, 2019; Rodriguez \& Goldman, 1995), it is still a matter of debate, specifically because of the violation of the linearity assumption. We therefore perform logistic regressions in the robustness checks section, the results of which are practically similar to those of our linear regression models.

We use a stepwise approach as this enables us to assess to what extent the effect of participation in $\mathrm{AE}$ is genuine or simply reflects that of other influences. It also allows us to examine to what degree this effect is mediated by different dimensions of AE. The first model only includes the effect of AE participation on volunteering. In the next step, we add the control 
Does participation in adult education increase volunteering?

variables and in the third model, we further include the variables for the different dimensions of AE.

\section{Results}

Before we present the results of our multivariate models, we look into some descriptive statistics for adult education participation and volunteering that are based on the total longitudinal sample.

In our sample, we observe $31 \%$ of the respondents changing their adult education behaviour and $22 \%$ of the respondents changing their volunteering behaviour. This shows that adult education behaviour is more volatile than volunteering. The change is equally distributed among starting $(8.7 \%)$ and ending $(8.7 \%)$ volunteering, while $4.8 \%$ of the respondents both started and ended volunteering in the given period. $67.8 \%$ of all respondents never volunteered in the observed years and $10.0 \%$ volunteered throughout. As far as adult education is concerned, $61.0 \%$ never took part within twelve months prior to the interview dates, $7.6 \%$ always did, $11.0 \%$ started, $13.3 \%$ ended and $7.0 \%$ ended and started adult education.

In the supplementary material, we report the proportions of participation in different types of adult education and volunteering by volunteering, sex, education, employment status and age groups. These statistics give important insights about how participation in adult education and volunteering is distributed among key socio-demographic groups, which our main analysis does not show, since it solely measures change.

\section{Multivariate Results}

Table 2 shows the results of our main analyses. Model 1 is the single predictor model estimating the chance to start volunteering as a function of participation in AE. The effect of participation in $\mathrm{AE}$ on volunteering is positive and significant (0.040). Controlling for potential time-invariant confounders, taking up an AE course increases the chance to take up volunteering by $4 \%$. 
Does participation in adult education increase volunteering?

Model 2 extends Model 1 by including time-variant controls. To retain legibility of Table 2, we only display the significant estimates among the estimates of the control variables, while we shift the remaining estimates to Appendix A1. Apart from an unsubstantial decrease in size, the effect of AE participation on volunteering stays the same. This result suggests that the effect neither proxies for one or more third factors, nor that any of the controls mediate the effect.

A short excursion to the estimates of the controls shows that the size of the effect of $\mathrm{AE}$ participation on volunteering (0.039) is quite substantial not only on its own but also in comparison to the other effect sizes. We find small positive effects of taking care of someone, age, a good health, interest in politics, retirement and unemployment (as compared to selflemployment) on volunteering. There are negative effects on volunteering associated with the year 2012/2013, moving houses and living together with the partner as compared to living alone. The only result that stands out is that starting to volunteer becomes $12 \%$ more likely if there is another adult in the household, who also took up volunteering.

Model 3 extends Model 2 by adding the four variables measuring different dimensions of AE. The effects go in the hypothesized directions with a negative effect of job-related AE as compared to AE for mixed purposes (as the reference category) and a positive effect of non-jobrelated $\mathrm{AE} .^{3}$ Further, the effects of volume of $\mathrm{AE}$ and of obtaining a qualification with $\mathrm{AE}$ are positive. However, none of these effects is significant and only the effect of non-job-related AE is substantial in size. These results suggest that neither content, nor qualification, nor volume matter for AE to increase the chance to volunteer. Moreover, the inclusion of the four variables hardly reduces the effect of AE participation, suggesting that the latter is not mediated by the nature and purpose of $\mathrm{AE}$. In other words, irrespective of the type, duration or purpose of $\mathrm{AE}$, taking up AE increases, on average, the chance of taking up volunteering by $4 \%$. 
Does participation in adult education increase volunteering?

Table 2

Linear probability person fixed effects models of adult education on volunteering.

\begin{tabular}{llll}
\hline & 1 & 2 & 3 \\
\hline Participation in AE & $0.040^{* * *}$ & $0.039^{* * *}$ & $0.032^{* * * *}$ \\
& $(0.00)$ & $(0.00)$ & $(0.01)$ \\
Purpose of AE (Ref=mixed) & & & -0.001 \\
Job-related AE & & $(0.01)$ \\
Non-job-related AE & & 0.017 \\
Qualification & & $(0.01)$ \\
Volume adult education & & 0.009 \\
& & $(0.01)$ \\
\hline
\end{tabular}

\begin{tabular}{|c|c|c|c|}
\hline \multirow{2}{*}{\multicolumn{4}{|c|}{$\begin{array}{l}\text { Control variables } \\
\text { Housing situation (Ref =living alone) }\end{array}$}} \\
\hline & & & \\
\hline \multicolumn{2}{|c|}{ With partner } & $\begin{array}{l}-0.025^{*} \\
(0.01)\end{array}$ & $\begin{array}{l}-0.026^{*} \\
(0.01)\end{array}$ \\
\hline \multicolumn{2}{|l|}{ With other adult(s) } & $\begin{array}{l}-0.014 \\
(0.01)\end{array}$ & $\begin{array}{l}-0.014 \\
(0.01)\end{array}$ \\
\hline \multicolumn{4}{|c|}{ Employment status (Ref.=self-/employed) } \\
\hline \multicolumn{2}{|c|}{ Unemployed/disabled } & $\begin{array}{l}0.034^{* * *} \\
(0.01)\end{array}$ & $\begin{array}{l}0.034^{* * *} \\
(0.01)\end{array}$ \\
\hline \multicolumn{2}{|l|}{ Pensioner } & $\begin{array}{l}0.045^{* * *} \\
(0.01)\end{array}$ & $\begin{array}{l}0.044^{* * * *} \\
(0.01)\end{array}$ \\
\hline \multicolumn{2}{|l|}{ Homemaker/else } & $\begin{array}{l}-0.000 \\
(0.01)\end{array}$ & $\begin{array}{l}-0.000 \\
(0.01)\end{array}$ \\
\hline \multicolumn{2}{|l|}{ Other volunteer in hh } & $\begin{array}{l}0.116^{* * *} \\
(0.01)\end{array}$ & $\begin{array}{l}0.116^{\text {**** }} \\
(0.01)\end{array}$ \\
\hline \multicolumn{2}{|l|}{ Interest in Politics } & $\begin{array}{l}0.010^{*} \\
(0.00)\end{array}$ & $\begin{array}{l}0.010^{*} \\
(0.01)\end{array}$ \\
\hline \multicolumn{2}{|l|}{ Good health } & $\begin{array}{l}0.016^{* * *} \\
(0.01)\end{array}$ & $\begin{array}{l}0.016^{* *} \\
(0.01)\end{array}$ \\
\hline \multicolumn{2}{|l|}{ Age } & $\begin{array}{l}0.026^{* * *} \\
(0.01)\end{array}$ & $\begin{array}{l}0.026^{* * *} \\
(0.01)\end{array}$ \\
\hline \multicolumn{2}{|l|}{$\mathrm{Age}^{2}$} & $\begin{array}{l}-0.000^{* * *} \\
(0.00)\end{array}$ & $\begin{array}{l}-0.000^{* * * *} \\
(0.00)\end{array}$ \\
\hline \multicolumn{2}{|l|}{ Moved houses } & $\begin{array}{l}-0.015^{*} \\
(0.01)\end{array}$ & $\begin{array}{l}-0.015^{*} \\
(0.01)\end{array}$ \\
\hline \multicolumn{2}{|l|}{ Cares for someone } & $\begin{array}{l}0.020^{\text {*** }} \\
(0.00)\end{array}$ & $\begin{array}{l}0.020^{* * * *} \\
(0.00)\end{array}$ \\
\hline \multicolumn{2}{|l|}{ 2012/2013 (Ref. $=2010 / 2011)$} & $\begin{array}{l}-0.027^{*} \\
(0.01)\end{array}$ & $\begin{array}{l}-0.027^{*} \\
(0.01)\end{array}$ \\
\hline \multicolumn{4}{|l|}{ Table 2 continued. } \\
\hline Constant & $\begin{array}{l}0.200^{* * * *} \\
(0.00)\end{array}$ & $\begin{array}{l}0.615^{* * *} \\
(0.08)\end{array}$ & $\begin{array}{l}0.615^{* * *} \\
(0.08)\end{array}$ \\
\hline$N$ & 62,569 & 62,569 & 62,569 \\
\hline
\end{tabular}


Does participation in adult education increase volunteering?

\section{Robustness checks}

We are aware of a number of limitations to our analytical strategy. Therefore, we conducted several robustness checks to test our main findings. Details to every robustness check are to be found in the supplementary material.

First, the assumption of linearity is violated in our main models, since we are measuring volunteering with a binary variable. This may result in faulty standard errors and therefore unreliable results. To account for this problem, we run logistic regressions. The effects of these regressions are identical to the ones we presented in Table 2 in terms of direction and significance level (see Supplementary Table 3).

Second, it is possible that our decisions in the variable constructions influence our results. This is both the case for the measure of volunteering and the measures of AE. In the main analysis, the measure of volunteering includes one-off activities. In one robustness check, we change the dummy of volunteering in the sense that one represents regular volunteering (at least once a month). Although this results in the effect of adult education decreasing to $2 \%$, the main findings hold (see Supplementary Table 3.1).

In a third robustness check, we changed the measurement of the content of AE. Instead of using the purpose, we make use of the provider of $\mathrm{AE}$ treating only employer provided $\mathrm{AE}$ as job-related. Using this estimation of content does not substantially influence our main findings. However, the effect of non-job-related training here increases in size to 0.026 (see Supplementary Table 3, Model 1).

We also altered the measure of volume of AE. Instead of using the total number of hours, we used the total number of courses. The results remain the same (see Supplementary Table 3.2, 
Does participation in adult education increase volunteering?

Model 2). Finally, we used only information on the first course for content, qualification, and volume. Our results remain the same (see Supplementary Table 3.2, Model 3).

Fourth, we reassessed two decisions referring to the sample derivation. (1) We replicate the analysis based on the balanced sample, hence only including respondents, who were involved in all three waves. The results do not change (see Supplementary Table 4). (2) We conduct a robustness check exploiting the whole width of the UKHLS (which has an inflated presence of immigrants and ethnic minorities), thereby increasing the number of observations substantially to 91,298. Here, we find a significant and positive effect of AE that culminates in a qualification on volunteering of $1 \%$. At the same time, the effect size of AE drops to 3\% (see Supplementary Table 4). This finding suggests that obtaining a qualification does matter for the size of the effect of $\mathrm{AE}$ on volunteering in specific cases. Obtaining a qualification might lead to a more significant increase in resources and self-efficacy relevant for volunteering for immigrants and ethnic minorities than for white British citizens.

\section{Discussion}

In this article, we posed the question whether $\mathrm{AE}$ increases volunteering, and whether its effectiveness depends on the type of AE. In our theoretical discussion, we proposed four hypotheses. Only the first hypothesis was confirmed by our results, which leads us to draw two major conclusions.

First, our models confirm the positive association between $\mathrm{AE}$ and volunteering. On average, participation in $\mathrm{AE}$ increases the likelihood to start volunteering (Hypothesis 1) by roughly 4\%. This finding is in accordance with earlier findings, regarding the significance and direction of the association. However, earlier studies using less restrictive models found much stronger associations (e.g. 70\% in Vera-Toscano et al., 2017). Hence, our contribution is that we 
Does participation in adult education increase volunteering?

reduced the problem of unobserved heterogeneity substantially and therefore were able to estimate a more plausible effect size.

Second, our results do not show significant effect differences for job-related versus nonjob-related $\mathrm{AE}$ (Hypothesis 4), for $\mathrm{AE}$ that leads up to a qualification versus $\mathrm{AE}$ that does not (Hypothesis 3) and for a varying volume of AE (Hypothesis 2). This is in contradiction to earlier research that did find influences of qualification, content, and volume (Feinstein et al., 2003). Our findings suggest that AE on average has a positive effect on volunteering, and an effect that does not vary substantially between different kinds of AE when controlling for stable individual characteristics.

Theoretically, these findings provisionally suggest that the mechanisms through which participation in $\mathrm{AE}$ leads to greater volunteering are not related to the content, qualification or volume of AE. Likely candidates for such mechanisms are (1) the expansion of one's social network and (2) the enhancement of one's self-efficacy as these have been identified as outcomes of participation in $\mathrm{AE}$ in general rather than participation in $\mathrm{AE}$ of a particular kind (as noted before). Our results speak in favour of these mechanisms, but there is, of course, also the possibility that adults decide to volunteer and to take part in AE completely independently. In our analyses, we do not directly test the mechanisms.

While our main findings do not support the assumption that a qualification generates further resources that increase the chance to volunteer, we did find a positive effect in one of our robustness checks when using a different sample. Future analyses could investigate how the types of qualifications obtained via AE differ between subgroups to shed light on the possibility that specific qualifications prevalent among specific social groups could have a strong impact on volunteering. 
Does participation in adult education increase volunteering?

Finally, we surmised that preferences as well as qualifications and perceived benefits related to volunteering could only change with $\mathrm{AE}$ if the content could somehow relate to the field of volunteering. Assuming that job-related courses would relate less to this field than nonjob related ones, we expected job-related courses to have a smaller impact on volunteering. However, we found no support for this hypothesis. Hence, either, the proposed mechanisms are not essential on average for an effect of non-job related AE on volunteering, or they may also be triggered by job-related AE. Skills that were acquired via job-related AE can be important skills for volunteering as well.

There are two more explanations why our results are not in agreement with earlier findings. First, earlier research was not able to control for as many individual factors as we were able to. Hence, this research may have overlooked individual level factors that both drive individuals into specific AE courses and that make individuals more prone to volunteering. The second plausible interpretation is that our categories are too broad to be able to differentiate an effect of the content or the qualification of AE, since we only observe average effects. Related to this point, it is also possible that the quality of $\mathrm{AE}$ matters for an effect related to a change in preferences. In our study, we could not control for the quality of AE.

One limitation of our work is that we cannot rule out reversed causality. In our model, the possibility cannot be ruled out that starting to volunteer leads to participation in AE. This can happen, for instance, if volunteering jobs, such as assisting in classrooms or taking part in neighbourhood watch initiatives, evoke an interest in a particular profession and a concomitant desire to undertake further education as a means of becoming qualified for this profession. Future research should pay close attention to the sequencing of volunteering and participation in AE to establish whether causality is unidirectional or reciprocal. 
Does participation in adult education increase volunteering?

Focusing on the UK, on the one hand, provides us with the argument that everybody should be able to volunteer, since the infrastructure is well developed. On the other hand, it restricts the generalizability of our results. The effect of $\mathrm{AE}$ on volunteering may be much smaller in countries with a less popular volunteering sector. Furthermore, in our study, we were not able to provide a more detailed specification of volunteering. The effect of $\mathrm{AE}$ on volunteering may differ substantially between different types of volunteering. Future research may hence look into the effect of AE both on different types of volunteering and in different contexts.

Despite these limitations, we provide a substantial contribution to research on the wider benefits of $\mathrm{AE}$ and to research on changes in volunteering. We show that, regardless of significant changes in the nature of $\mathrm{AE}$, which would lead one to expect that it no longer contributes to volunteering, AE (still) positively influences volunteering. Therefore, the belief of politicians that civic participation can be enhanced by AE appears justified. When civic participation drops in the UK, fostering AE may be an effective intervention to, if not reverse, than at least slow down this fall. Moreover, our finding that participation in any AE is effective in fostering volunteering, can be read as an encouragement to support a wide variety of AE while having in mind its social outcomes and potential to raise self-efficacy. However, only if the effect of AE on volunteering is absolute rather than positional (cf. Nie et al. 1996), meaning that those who engage in $\mathrm{AE}$ do not crowd out those who do not regarding taking part in volunteering, can one expect an increase in $\mathrm{AE}$ participation rates to lead to an increase in volunteering in society as a whole. 
Does participation in adult education increase volunteering?

\section{Endnotes}

${ }^{1}$ There are 9 qualification levels in the UK with Level 1 being the lowest and Level 9 the highest level. Level 3 gives access to university and Levels 6 and 7 are university degrees. Detailed information on the educational levels may be drawn from the UK government website: https://www.gov.uk/what-different-qualification-levels-mean/list-of-qualification-levels .

2 (1) To help you get started in your job; (2) To improve your skills in your current job; (3) To maintain professional status and/or meet occupational standards; (4) To prepare you for a job you might do in the future; (5) To help you get a promotion; (6) Health and Safety Training; (7) For hobbies or leisure

${ }^{3}$ The reference group for the effects of the job-related and non-job related variables is only the group doing AE for both purposes and not the non-participants as the latter are already captured by the AE participation effect. The effects of the job-related and non-job-related variables do not change by changing the reference category (e.g. making job-related AE the reference category does not change the effect of non-job related AE). 
Does participation in adult education increase volunteering?

\section{References}

AUTHOR 1 and OTHERS (2018). (publication details withheld for anonymity)

AUTHOR 2 \& ANOTHER (2013). (publication details withheld for anonymity)

Balatti, J., \& Falk, I. (2002). Socioeconomic contributions of adult learning to community: A social capital perspective. Adult education quarterly, 52(4), 281-298.

Bekkers, R. (2005). Participation in voluntary associations: Relations with resources, personality, and political values. Political Psychology, 26(3), 439-454.

Bekkers, R. (2010). Who gives what and when? A scenario study of intentions to give time and money. Social Science Research, 39(3), 369-381.

Beyerlein, K., \& Bergstrand, K. (2016). It takes two: A dyadic model of recruitment to civic activity. Social science research, 60, 163-180.

Bilger, F., Behringer, F., Kuper, H., \& Schrader, J. (2017). Weiterbildungsverhalten in Deutschland 2016 - Ergebnisse des Adult Education Survey (AES). Bielefeld: wbv Media.

Boeren, E. (2017). Understanding adult lifelong learning participation as a layered problem. Studies in Continuing Education, 39(2), 161-175.

Bynner, J. (2017). Whatever happened to lifelong learning? And does it matter?. Journal of the British Academy, 5, 61-89. 
Does participation in adult education increase volunteering?

De Greef, M., Verté, D., \& Segers, M. (2015). Differential outcomes of adult education on adult learners' increase in social inclusion. Studies in Continuing Education, 37(1), 62-78.

Desjardins, R., Rubenson, K., \& Milana, M. (2006). Unequal chances to participate in adult learning: International perspectives. Paris: UNESCO.

Desjardins, R. (2017). Political Economy of Adult Learning Systems: Comparative Study of Strategies, Policies and Constraints. Bloomsbury: Bloomsbury Academic.

Dieckhoff, M., Jungblut, J.-M., \& O’Connell, P. (2007). Job-related training in Europe: Do institutions matter. In: Gallie, D. (ed) Employment regimes and the quality of work. Oxford: Oxford University Press, 77-104.

Dolan, P., Fujiwara, D., \& Metcalfe, R. (2012). Review and update of research into the wider benefits of adult learning. BIS research paper 90 .

Dolan, P., Peasgood, T., \& White, M. (2008). Do we really know what makes us happy? A review of the economic literature on the factors associated with subjective wellbeing. Journal of economic psychology, 29(1), 94-122.

Einolf, C., \& Chambré, S. M. (2011). Who volunteers? Constructing a hybrid theory. International Journal of Nonprofit and Voluntary Sector Marketing, 16(4), 298-310.

Feinstein, L., Hammond, C., Woods, L., Preston, J., \& Bynner, J. (2003). Wider benefits of learning research report, No. 8. The contribution of adult learning to health and social capital. London: Centre for Research on the Wider Benefits of Learning. Institute of Education. Retrieved from http://eprints.ioe.ac.uk/14854/1/WBLResRep8.pdf. 
Does participation in adult education increase volunteering?

Fujiwara, D. (2012). Valuing the Impact of Adult Learning. An analysis of the effect of adult learning on different domains in life. Leicester: NIACE. Retrieved from http://shop.niace.org.uk/media/catalog/product/v/a/valuingimpact_web_1.pdf.

Gomila, R. (2019). Logistic or linear? Estimating causal effects of treatments on binary outcomes using regression analysis. https://doi.org/10.31234/osf.io/4gmbv

Greenfield, E. A., \& Moorman, S. M. (2018). Extracurricular involvement in high school and later-life participation in voluntary associations. Journals of Gerontology Series B: Psychological Sciences and Social Sciences, Series B, 73(3), 482-491.

Hammond, C., \& Feinstein, L. (2005). The Effects of Adult Learning on Self-Efficacy. London Review of Education, 3(3), 265-287.

Hank, K., \& Stuck, S. (2008). Volunteer work, informal help, and care among the 50+ in Europe: Further evidence for 'linked'productive activities at older ages. Social Science Research, 37(4), 1280-1291.

Hanushek, E. A., Schwerdt, G., Woessmann, L., \& Zhang, L. (2017). General Education, Vocational Education, and Labor-Market Outcomes over the Lifecycle. Journal of Human Resources, 52(1), 48-87.

Hornung, L. (2018). Why people volunteer and why they stop - what the latest data tells us [Block post]. Retrieved from https://blogs.ncvo.org.uk/2018/03/22/why-peoplevolunteer-and-why-they-stop-what-the-latest-data-tells-us/. 
Does participation in adult education increase volunteering?

Hustinx, L., Cnaan, R. A., \& Handy, F. (2010). Navigating theories of volunteering: A hybrid map for a complex phenomenon. Journal for the theory of social behaviour, 40(4), 410434.

Kim, J., \& Morgül, K. (2017). Long-term consequences of youth volunteering: Voluntary versus involuntary service. Social science research, 67, 160-175.

Knoke, D., \& Thomson, R. (1977). Voluntary association membership trends and the family life cycle. Social Forces, 56(1), 48-65.

Lancee, B., \& Radl, J. (2014). Volunteering over the life course. Social Forces, 93(2), 833-862.

Lauglo, J., \& Øia, T. (2006). Education and civic engagement among Norwegian youths. Oslo: Norwegian Social Research.

Low, N., Butt, S., Ellis, P., \& Smith, D. J. (2007). Helping out: a national survey of volunteering and charitable giving. London: Cabinet Office.

Lynn, P., \& Borkowska, M. (2018). Some Indicators of Sample Representativeness and Attrition Bias for BHPS and Understanding Society (No. 2018-01). Understanding Society at the Institute for Social and Economic Research.

Manninen, J., Fleige, M., Thöne-Geyer, B., \& Kil, M. (2014). Benefits of lifelong learning in Europe: Main results of the BeLL-Project. Research Report. Bonn. Retrieved from http://www.bell-project.eu/cms/wp-content/uploads/2014/06/BeLL-Research-Report.pdf.

Mathou, C. (2010). Volunteering in the European Union. Brussels: GHK. 
Does participation in adult education increase volunteering?

McGarvey, A., Jochum, V., Davies, J., Dobbs, J., \& Hornung, L. (2019). Time well spent: A national survey on the volunteer experience. London. Retrieved from https://www.ncvo.org.uk/images/documents/policy_and_research/volunteering/Voluntee r-experience_Full-Report.pdf

Mood, C. (2010). Logistic regression: Why we cannot do what we think we can do, and what we can do about it. European sociological review, 26(1), 67-82.

Nie, N., Junn, J. and Stehlik-Barry, K. (1996) Education and Democratic Citizenship in America (Chicago, Chicago University Press).

Niebuur, J.; Van Lente, L.; Liefbroer, A.C.; Steverink, N.; Smidt, N. (2018). Determinants of participation in voluntary work: A systematic review and meta-analysis of longitudinal cohort studies. BMC Public Health, 18, 1213

Niemi, R. G., \& Junn, J. (1998). Civic education: what makes students learn. New Haven: Yale University Press.

Oesterle, S., Johnson, M. K., \& Mortimer, J. T. (2004). Volunteerism during the transition to adulthood: A life course perspective. Social Forces, 82(3), 1123-1149.

Olbrich, J. (2001). Geschichte der Erwachsenenbildung in Deutschland. Heidelberg: SpringerVerlag.

Panitsidou, E. A. (2012). Wider Benefits of adult participation in Lifelong Learning courses. MENON: Journal of Education Research, 1, 45-52. 
Does participation in adult education increase volunteering?

Paterson, L. (2009). Civic values and the subject matter of educational courses. Oxford Review of Education, 35(1), 81-98.

Power, M. J., Neville, P., \& O’Dwyer, M. (2011). The social value of community-based adult education in Limerick city. Limerick: Limerick City Adult Education Service. Retrieved from http://www.paulpartnership.ie/wp-content/uploads/2012/04/Community-basedAdult-Ed-FULL-d3.pdf.

Priemer, J., Krimmer, H., \& Labigne, A. (2017). ZiviZ-Survey 2017 - Vielfalt verstehen. Zusammenhalt stärken. Essen: SV Verwaltungsgesellschaft für Wissenschaftspflege $\mathrm{mbH}$.

Putnam, R. D. (2000). Bowling alone: America's declining social capital. Culture and politics, 223-234. New York: Palgrave Macmillan.

Qvist, H.-P. Y., \& Munk, M. D. (2018). The Individual Economic Returns to Volunteering in Work Life. European Sociological Review, 34(2), 198-210.

Rodriguez, G., \& Goldman, N. (1995). An assessment of estimation procedures for multilevel models with binary responses. Journal of the Royal Statistical Society. Series A (Statistics in Society), 158 (1), 73-89.

Rotolo, T. (2000). A time to join, a time to quit: The influence of life cycle transitions on voluntary association membership. Social Forces, 78(3), 1133-1161.

Ruhose, J., Thomsen, S. L., \&Weilage, I. (2019). The Benefits of Adult Learning: WorkRelated Training, Social Capital, and Earnings. Economics of Education Review. 
Does participation in adult education increase volunteering?

Schuller, T., Preston, J., Hammond, C., Brassett-Grundy, A., \& Bynner, J. (2004). The Benefits of Learning. The impact of education on health, family life and social capital. London: Routledge Falmer.

Son, J., \& Lin, N. (2008). Social capital and civic action: A network-based approach. Social Science Research, 37(1), 330-349.

Tett, L., \& Maclachlan, K. (2007). Adult literacy and numeracy, social capital, learner identities and self-confidence. Studies in the Education of Adults, 39(2), 150-167.

Thomas, E. (2017). The outcomes and impacts of everyday learning. International Journal of Lifelong Education, 36(3), 308-323.

Tønseth, C. (2015). Adults in the "new" competence regime - Acquiring "the sense of the game”. New Horizons in Adult Education and Human Resource Development, 27(4), 418.

University of Essex. Institute for Social and Economic Research, NatCen Social Research, \& Kantar Public (2017). Understanding Society: Waves 1-7, 2009-2016 and Harmonised BHPS: Waves 1-18, 1991-2009. [data collection]. 9th Edition. UK Data Service. SN: 6614. doi.org/10.5255/UKDA-SN-6614-10.

Vera-Toscano, E., Rodrigues, M., \& Costa, P. (2017). Beyond educational attainment: The importance of skills and lifelong learning for social outcomes. Evidence for Europe from PIAAC. European Journal of Education, 52(2), 217-231. 
Does participation in adult education increase volunteering?

Wiertz, D. (2016). Segregation in civic life: Ethnic sorting and mixing across voluntary associations. American Sociological Review, 81(4), 800-827.

Wilson, J. (2012). Volunteerism research: A review essay. Nonprofit and Voluntary Sector Quarterly, 41(2), 176-212. 
Does participation in adult education increase volunteering?

\section{Appendix}

\section{Appendix A1 - Continuation of Table 2}

Table 2 - continued. Linear probability person fixed effects models of adult education on volunteering.

\begin{tabular}{lll}
\hline & 2 & 3 \\
\hline Marital Status (Ref.=Single) & -.001 & -.001 \\
Married & $(.01)$ & $(.01)$ \\
& -.007 & -.007 \\
Separated/widowed & $(.01)$ & $(.01)$ \\
Child in hh & -.013 & -.013 \\
& $(.01)$ & $.01)$ \\
Net Income & -.000 & -.000 \\
& $(.00)$ & $(.00)$ \\
Change in employment & -.007 & -.007 \\
Subjective financial difficulties (Ref.=No) & $(.02)$ & $(.01)$ \\
Some & .003 & .003 \\
Yes & $(.00)$ & $(.00)$ \\
& .012 & .012 \\
Year (Ref.=2010/2011) & $(.01)$ & $(.01)$ \\
2014/2015 & & -.046 \\
& -.046 & $(.02)$ \\
\hline
\end{tabular}

Source: Own calculations using UKHLS, wave 2, 4, 6.

Note: Standard errors in parentheses. Estimates of control variables that displayed insignificant effects. Models also include participation in AE, housing situation, employment status, other volunteer in hh, interest in politics, good health, age, age ${ }^{2}$, moved houses, cares for someone, year 2012/2013.

${ }^{*} p<0.05,{ }^{* *} p<0.01,{ }^{* * *} p<0.001$ 